\title{
Antiplatelets in secondary stroke prevention
}

\author{
Olga Shulga' and Natan Bornstein ${ }^{2 *}$ \\ 1 Department of Neurology, Volyn Regional Clinical Hospital, Lutsk, Ukraine \\ 2 Stroke Unit, Department of Neurology, Tel-Aviv Sourasky Medical Center, Tel-Aviv, Israel
}

\section{Edited by:}

Laszlo Csiba, University of Debrecen and Health Science Center, Hungary

\section{Reviewed by:}

Edward Feldmann, Brown University, USA

Vincent Thijs, University Hospitals

Leuven, Belgium

Laszlo Csiba, University of Debrecen and Health Science Center, Hungary

\section{*Correspondence:}

Natan Bornstein, Department of Neurology, Tel-Aviv Sourasky Medical

Center, 6 Weizmann Street, Tel-Aviv

64239, Israel.

e-mail:strokeun@tasmc.gov.il
The aim of this review is to provide evidence-based recommendations on the secondary prevention of atherothrombotic ischemic stroke. Antiplatelets are the major therapy for the secondary stroke prevention. The most commonly used antiplatelets agents are aspirin, clopidogrel, and extended-release dipyridamole. A lot of progress had been made in last years regarding aspirin resistance and genotyping of clopidogrel metabolism. According to the results of the accomplished studies it is difficult to broadly recommend one antithrombotic agent in favor of the other. Instead, a review of the currently published data suggests the importance of focusing on the individualizing approach in antiplatelet therapy.

Keywords: ischemic stroke, secondary prevention, antiplatelets

\section{INTRODUCTION}

Reducing the high risk of a recurrent stroke is an important component of the management of patients with ischemic stroke or a recent transient ischemic attack (TIA). Recurrent strokes are particularly dangerous (Hankey et al., 2007). Approximately 60-70\% of first recurrent strokes have the same mechanism as the incident stroke (Shin et al., 2005).

Stroke patients often have coronary or peripheral artery disease (PAD), and increased risks of cardiovascular death. (Steg et al., 2007). Therefore, secondary stroke prevention depends upon stroke subtypes and concomitant cardiovascular disorders (Ohira et al., 2006).

In patients with TIA or ischemic stroke of non-cardiac origin antiplatelets drugs are able to decrease the risk of stroke by $11-15 \%$. And the composite risk of stroke, myocardial infarction (MI), and vascular death is 15-22\% (Antithrombotic Trialists' Collaboration, 2002).

This review focuses on evidence-based recommendations for secondary prevention of atherothrombotic ischemic stroke.

\section{ASPIRIN}

Aspirin (Acetylsalicylic acid, ASA) has a long history in the area of secondary stroke prevention. It is the main comparator agent in many recurrent stroke prevention trials, and the subject of many metareviews or systematic analyses. Aspirin is relatively safe, easy to administer, and readily available.

Aspirin irreversibly inhibits cyclooxygenase- 1 (COX-1) in platelets by acetylating its serine-529 residue, thereby blocking thromboxane 2 (TXA2) and other eicosanoid production from arachidonic acid. COX-1-dependent TXA2 inhibition lasts throughout a platelet's lifespan (7-10 days), thereby aspirin effects are maintained with daily dosing intervals. Aspirin induced COX1 inhibition is rapid and irreversible (Roth and Calverley, 1994). After a single $325 \mathrm{mg}$ dose of ASA, platelet COX-1 activity is completely inhibited and recovers by about $10 \%$ per day, due to nascent platelet release in the circulation. After a single dose, a peak value is reached in about $1 \mathrm{~h}$ and then declines gradually, with a half-life of about 2-3 h at antiplatelet doses (Brunton et al., 2005).

In meta-analysis of all randomized clinical trial (RCTs) conducted in ischemic stroke or TIA patients comparing aspirin in different doses to placebo, it was found that aspirin reduces the risk of recurrent stroke and other major vascular events by $13 \%$ (95\% CI, 6-19\%; Algra and van Gijn, 1999).

The overview analysis of an indirect comparisons between the various doses of aspirin suggests that aspirin doses as low as $30 \mathrm{mg} /$ day to as high as about $1300-1500 \mathrm{mg} /$ day have the same point estimate of efficacy for recurrent stroke prevention, but lower-dose aspirin use is associated with fewer side effects (The Dutch TIA Trial Study Group, 1991). Some experts suggest an aspirin dose of $75-81 \mathrm{mg} /$ day as one providing the best safety and efficacy balance for cardiovascular disease prevention (Campbell et al., 2007).

The Antithrombotic Trialists' Collaboration had summarized the data from thousands of patients with stroke or TIA (mean duration of 29 months), those who had taken antiplatelet agents, primarily aspirin, in clinical trials. The data shows that serious vascular events are reduced by 36 per $1000(P=0.0001)$ driven by a reduction of non-fatal stroke by 25 per $1000(P=0.0001)$ with a smaller but significant reduction of non-fatal MI by $6 / 1000$ fewer $(P=0.0009)$ events (Antithrombotic Trialists' Collaboration, 2002).

The main adverse event in association with aspirin administration is bleeding complications.

Aspirin increases the risk of major bleeding by about 70\% [risk ratio (RR) 1.71 (95\% CI, 1.41-2.08)]. Low-dose aspirin increases the risk of major bleeding by $70 \%$, but the absolute increase is modest: 769 patients (95\% CI, 500-1250) need to be treated with aspirin to cause one additional major bleeding episode annually. The increased risk of bleeding is mainly due to an increase in major gastrointestinal bleeding [RR 2.07 (95\% CI, 1.61-2.66) 
with absolute annual increase $0.12 \% \quad(0.07-0.19 \%)]$ and intracranial bleeding $[\mathrm{RR} 1.65$ (1.06-5.99); with absolute annual increase $0.03 \%$ (0.01-0.08\%; McQuaid and Laine, 2006). Therefore, to minimize major adverse events associated with aspirin administration such as bleeding and maintain efficacy, the dose of aspirin approved by the US Food and Drug Administration (FDA) is in the range of 50-325 mg/day (Campbell et al., 2007).

An important issue which recently has been discussed extensively is aspirin resistance. The estimated prevalence of aspirin resistance is $5.5-60 \%$, depending on the type of analyzer and definition used (Antithrombotic Trialists' Collaboration, 2002). Some major cardiovascular disease prevention guidelines do not recommend routine use of platelet function testing in clinical practice.

It is important to keep in mind that stroke recurrence at the time of taking aspirin does not always equate with aspirin "failure" (Selim and Molina, 2010). Concomitant use of non-steroidal anti-inflammatory drugs reduces the efficacy of aspirin. The problem is that most of the current available laboratory methods of platelet function assays have not been standardized or been shown to reliably distinguish individual patients at high risk (Eikelboom et al., 2010).

\section{TRIFLUSAL}

Triflusal is an antiplatelet agent that is structurally related to aspirin. It has an antithrombotic effect by acting on various targets involved in platelet aggregation and vascular inflammatory processes. Triflusal also increases nitric oxide synthesis in neutrophils resulting in increased vasodilatory potential. Unlike aspirin, triflusal did not increase bleeding time. In Cochrane Review the results of five studies on efficacy of triflusal in secondary stroke prevention were analyzed (four trials after stroke and TIA, 2944 patients followed for 6 -47 months and one trial after acute MI). No significant differences were found between triflusal and aspirin for secondary prevention of serious vascular events in patients with stroke or TIA and acute MI (Costa et al., 2005). Triflusal was associated with a lower risk of hemorrhagic complications.

Another drug for secondary stroke prevention is ticlopidine, a thienopyridine derivative. The efficacy of ticlopidine was shown in placebo-controlled studies. However serious side effects of ticlopidine (bone marrow depression, rash, and diarrhea) put to use a new drug clopidogrel (Gorelick et al., 2003).

\section{CLOPIDOGREL}

Both clopidogrel and ticlopidine are thienopyridine derivative. Clopidogrel blocks the adenosine diphosphate (ADP) pathway of platelet aggregation.

Clopidogrel is an inactive prodrug that requires two-step oxidation by the hepatic cytochrome P450 (CYP) system to generate its active compound, which irreversibly inhibits the ADP P2Y purinoceptor 12 on circulating platelets. Clopidogrel reaches its maximum antiplatelet activity within $4-5$ days. This should be taken into account when starting clopidogrel for stroke prevention. Pharmacokinetic and pharmacodynamic response to clopidogrel depends on genetic polymorphisms (Mega et al., 2009; Schuldiner et al., 2009). The genome-wide association study of clopidogrel response has reported that the loss of function CYP2C19*2 genotype (the most common genetic variant) is associated with poor metabolism of clopidogrel and poorer outcome (Schuldiner et al., 2009). The CYP2C19^2 polymorphism accounts for only $12 \%$ of variability in clopidogrel platelet response and is associated with higher cardiovascular risks. Those are independent from the diminished conversion of the prodrug to the active form of clopidogrel. A genomic profile may identify patients at risk of ischemic event but its use in everyday practice is very limited in the present time (Holmes et al., 2010).

To minimize the risk of gastrointestinal bleeding complications, concomitant administration of clopidogrel with a proton pump inhibitor (PPIs), also decrease clopidogrel's antiplatelet action in a one-third of patients (Siller-Matula et al., 2009). Therefore PPIs should not be used in combination with clopidogrel.

The efficacy of clopidogrel ( $75 \mathrm{mg}$ daily) in preventing recurrent vascular events in patients who suffered a recent MI, stroke or symptomatic established PAD comparing with aspirin (325 mg daily) was approved in CAPRIE (Clopidogrel vs. Aspirin in Patients at Risk of Ischemic Events study). CAPRIE was a large ( $n=19,185$ patients at 384 clinical centers), a randomized, blinded, international trial for a mean follow-up of 1.91 years. Patients were enrolled in three diagnostic strata: ischemic stroke (6431 patients), MI (6302 patients), and PAD (6452 patients).The primary end point was risk of non-fatal MI, ischemic stroke, or vascular death. The rate of the composite outcome per year was $5.32 \%$ for clopidogrel and $5.83 \%$ for aspirin, or an $8.7 \%$ relative risk reduction (RRR; $P=0.043$ ) favoring clopidogrel (CAPRIE Steering Committee, 1996).

The most significant difference between clopidogrel and aspirin was observed in the PAD group (RRR for clopidogrel vs. aspirin, $23.8 \% ; P=0.0028)$. In the stroke group, the benefit for clopidogrel was smaller and statistically non-significant (RRR 7.3\%, $P=0.28$ ). In the MI group, aspirin had greater efficacy, although the difference once again was not statistically significant (RRR $3.7 \% ; P=0.56)$. The results of CAPRIE study suggest greater efficacy for clopidogrel as compared with aspirin after symptomatic PAD than after MI or stroke (Gorelick et al., 1999). However the study was not powered to perform sub-group analysis and these results should be taken with caution. A post hoc analysis of the CAPRIE data revealed that patients with a history of coronary artery bypass grafting, who received clopidogrel had an RRR of $28.9 \%$ compared with patients receiving aspirin.

As well as a grater benefit from clopidogrel comparing to aspirin therapy in diabetic patients. The event rate for vascular death, ischemic stroke, MI, or re-hospitalization or bleeding was $17.7 \%$ in patients with diabetes taking aspirin and $15.6 \%$ in patients taking clopidogrel with absolute risk reduction by $2.1 \%$ and number needed to treat of 48 per year. The adverse event profiles for clopidogrel and aspirin were similar, and both agents were relatively well tolerated. In CAPRIE the non-fatal primary intracranial hemorrhage and hemorrhagic death was less frequent in the clopidogrel group $(0.39 \%)$ than in aspirin group $(0.53 \%)$. Because of the small, absolute risk reduction of $0.5 \%(\mathrm{NNT}=200$ per year) and the low cost of aspirin, clopidogrel is not recommended in many countries as the drug of first choice in patients after cerebral ischemia.

Following the success of the CURE study in acute coronary syndrome (The Clopidogrel in Unstable Angina to Prevent Recurrent 
Events Trial Investigators, 2001) the next clopidogrel study focused on stroke prevention was management of atherothrombosis in high-risk patients with recent TIA or ischemic stroke (MATCH) trial. It included 7599 patients with recent stroke or TIA and other vascular risk factors (diabetes or a previous stroke, MI, or PAD) randomized to treatment with clopidogrel alone or clopidogrel plus aspirin. The primary outcome was the composite of MI, ischemic stroke, vascular death, or re-hospitalization for an acute ischemic event. The combination of aspirin plus clopidogrel treatment group showed favor of the combination (16.73\% vs. $15.7 \%$ ). The RRR was $6.4 \%$ and the result was not statistically significant $(P=0.244)$. It was observed in this study an approximate threefold increased risk of life-threatening ( 3 vs. $1 \% ; P=0.0001$ ) and two-fold increased risk of major ( 2 vs. $1 \% ; P=0.0001$ ) bleeding (intracranial or gastrointestinal hemorrhages) in the aspirin plus clopidogrel group (Diener et al., 2004). MATCH investigators concluded that the addition of aspirin to clopidogrel in high-risk stroke and TIA patients did not provide additional clinical benefit to clopidogrel alone and increased the risk of life-threatening and major bleeds.

Another RCT, clopidogrel for high atherothrombotic risk and ischemic stabilization, management, and avoidance (CHARISMA) tested aspirin $75-162 \mathrm{mg} /$ day and clopidogrel $75 \mathrm{mg} /$ day or placebo (Bhatt et al., 2006). There were over 15,000 randomized patients with symptomatic cardiovascular disease $(n=12,153)$ or multiple risk factors ( $n=3284$; Hankey et al., 2007). The primary endpoint was the composite of vascular death, non-fatal stroke, and non-fatal MI. The CHARISMA showed a RRR of 7\% (95\% CI, 0.5-17) in favor of the combination of clopidogrel plus aspirin, but this was not statistically significant $(P=0.22$; Bhatt et al., 2006). For the secondary endpoint, which included the primary endpoint plus hospitalization for unstable angina, TIA, or a revascularization procedure, a small but statistically significant result favoring the clopidogrel plus aspirin treatment was noted (RRR 8\%; 95\% CI, 0.5-14; $P=0.04$ ). An adjudicated first stroke during follow-up (recurrent stroke) occurred in 233 patients, of whom 103 were randomly assigned clopidogrel and 130 to placebo (RRR 20\%, 95\% CI, 3-38). Most strokes were ischemic [ $n=202$ of 233 (87\%); 91 patients assigned clopidogrel vs. 113 on placebo]. A few strokes were hemorrhagic $[n=19$ of 236 (8\%); 10 clopidogrel vs. 9 placebo]. Only 12 strokes were of unknown type (Hankey et al., 2010). Non-fatal ischemic stroke was reported to be reduced in the combination antiplatelet treatment group but was not statistically significant $(1.7 \%$ vs. $2.1 \%$; RRR $18 \%$, $P=0.10$ ), and non-fatal stroke was reduced by combination therapy as well ( $1.9 \%$ vs. $2.4 \%$; RRR $20 \%, P=0.05)$. In analysis of the patients with documented prior MI, ischemic stroke, or symptomatic PAD significant benefit was observed from dual-antiplatelet therapy with clopidogrel plus aspirin. Patients with prior stroke $(n=3245)$ showed significant benefit from aspirin plus clopidogrel (Hazard Ratio 0.78, 95\% CI, 0.624-0.976; $P=0.029$; Bhatt et al., 2007).

The fast assessment of stroke and TIA to prevent early recurrence (FASTER) trial was designed to test the effectiveness of combination therapy compared with aspirin alone for preventing stroke among patients with a TIA or minor stroke within the previous $24 \mathrm{~h}$. The trial was stopped early because of slow recruitment. Results were inconclusive (Kennedy et al., 2007).
Initiation of treatment with clopidogrel in a daily dose of $75 \mathrm{mg}$ does not cause maximal platelet inhibition for 5 days (Qureshi et al., 2000). This delay poses the issue of an early therapeutic effect for treatment of patients with acute stroke. A bolus dose of clopidogrel $300 \mathrm{mg}$ inhibits platelet aggregation rapidly (Gurbel et al., 2003).

The efficacy of clopidogrel in secondary stroke prevention was studied in the atrial fibrillation clopidogrel trial with irbesartan for prevention of vascular events (ACTIVE A). It was compared the combination of aspirin plus clopidogrel with aspirin alone for the prevention of major vascular events in patients with atrial fibrillation who had an increased risk of stroke and in whom therapy with a vitamin $\mathrm{K}$ antagonist was considered to be unsuitable. The patients were randomly assigned to receive clopidogrel at a dose of $75 \mathrm{mg}$ or matching placebo once daily, in a double-blind fashion. All patients also received aspirin (recommended dose, 75$100 \mathrm{mg} /$ day). The primary study outcome was any major vascular event (stroke, non-central nervous system systemic embolism, MI, or death from vascular causes). The most important secondary outcome was stroke. At a median of 3.6 years of follow-up, stroke occurred in 296 patients receiving clopidogrel (2.4\% per year) and 408 patients receiving placebo (3.3\% per year; relative risk $0.72 ; 95 \% \mathrm{CI}, 0.62-0.83 ; P<0.001)$. Major bleeding occurred in 251 patients receiving clopidogrel (2.0\% per year) and in 162 patients receiving placebo (1.3\% per year; relative risk, $1.57 ; 95 \%$ CI, 1.29-1.92; $P<0.001$; Connolly et al., 2009).

There are several ongoing studies in the efficacy of clopidogrel in secondary stroke prevention: platelet-Oriented inhibition in new TIA and minor ischemic stroke (POINT) Trial, clopidogrel in high-risk patients with acute non-disabling cerebrovascular events (CHANCE), comparison of triflusal and clopidogrel effect in secondary prevention of stroke based on the cytochrome P450 2C19 Genotyping (MAESTRO), combination of clopidogrel and aspirin for prevention of early recurrence in acute atherothrombotic stroke (COMPRESS; A Service of the US National Institutes of Health, http://clinicaltrials.gov/ct2/results?term=clopidogrel).

\section{ASPIRIN PLUS EXTENDED-RELEASE DIPYRIDAMOLE}

Dipyridamole inhibits the uptake of adenosine into platelets, endothelial cells, and erythrocytes in vitro and in vivo; the inhibition occurs in a dose-dependent manner at therapeutic concentrations $(0.5-1.9 \mathrm{mcg} / \mathrm{mL})$. This inhibition results in an increase in local concentrations of adenosine which acts on the platelet A2-receptor thereby stimulating platelet adenylate cyclase and increasing platelet cyclic- $3^{\prime}, 5^{\prime}$-adenosine monophosphate levels. Via this mechanism, platelet aggregation is inhibited in response to various stimuli such as platelet activating factor, collagen, and adenosine diphosphate.

The efficacy of aspirin plus extended-release dipyridamole (ER-DP) was evaluated in the second European stroke prevention study (ESPS-2). ESPS-2 was a randomized, double-blind, placebo-controlled factorial design study that compared aspirin $25 \mathrm{mg}$ twice a day plus ER-DP $200 \mathrm{mg}$ twice a day, both agents, and placebo for secondary prevention in 6602 patients with prior stroke or TIA followed for 2 years (The ESRS-2 Group. 1997). Both aspirin and ER-DP monotherapy reduced the risk of stroke vs. placebo (aspirin: RRR 18\%; $P=0.013$; ER-DP: RRR $16 \%$, 
$P=0.039)$. Aspirin and ER-DP reduces also the risk of a composite stroke or death outcome (aspirin: RRR 13\%; $P=0.016$; ER-DP: RRR $15 \%$; $P=0.015)$. Aspirin plus ER-DP reduced the relative risk of stroke by $23 \%$ compared with aspirin alone $(P=0.001)$, and the relative risk of stroke, $\mathrm{MI}$, and sudden death by $20 \% \mathrm{com}-$ pared with aspirin alone $(P=0.005)$. The combination of aspirin plus ER-DP was twice as efficacious as either agent alone (Diener et al., 1996).

The most common adverse event associated with ER-DP was headache. It was observed in $24-70 \%$ of patients, usually within the first 3 months. Headache is more likely to occur in women, non-smokers, and patients with an absence of relevant ischemic lesions on brain imaging (Halkes et al., 2006) Both all-site and gastrointestinal bleeding were significantly more frequent with aspirin (Diener et al., 1996). In meta-analysis, the results of ESPS2 to the nine other placebo-controlled trials does not appreciably change the relative risk of any major bleeding with aspirin (1.76, 95\% CI, 1.45-2.12).

The European/Australasian stroke prevention in reversible ischemia trial (ESPRIT) was developed in part to answer questions related to uncertainty over the results of the ESPS-2. ESPRIT was established and carried out by an academic group in the Netherlands (Halkes et al., 2006). Budget limitations and the desire to capture real-life practice situations led to an open-label trial that compared aspirin with aspirin plus dipyridamole. There were recruited patients with TIA or ischemic stroke $(n=2739)$ with a mean follow-up for 3.5 years. There was a $20 \%$ reduction of the main outcome endpoint (composite of vascular death, non-fatal stroke, non-fatal MI, or major bleeding) in favor of the aspirin plus dipyridamole (Ohira et al., 2006). Combination therapy was safe and did not lead to cardiac complications, which were findings similar to those in ESPS-2. Headache was a major reason for discontinuation of treatment which was also the case with combination therapy in ESPS-2 (Halkes et al., 2009).

The effects of aspirin plus ER-DP vs. clopidogrel and telmisartan in ischemic stroke patients were studied in the prevention regimen for effectively avoiding second strokes (PRoFESS; Sacco et al., 2008). It was a double-blind, active, and placebo-controlled study which included 20,332 patient with a mean follow-up for a median 2.4 years. The primary endpoint was rate of first recurrent stroke. Recurrent strokes occurred in 916 (9\%) patients randomly assigned to ASA with ER-DP and 898 (9\%) patients randomly assigned to clopidogrel; 880 (9\%) patients randomly assigned to telmisartan and 934 (9\%) patients given placebo had recurrent strokes. Major hemorrhagic events were more common among patients assigned to aspirin and ER-DP (4.1\% compared with $3.6 \%$ ) but did not meet statistical significance. Adverse events leading to drug discontinuation ( $16.4 \%$ compared with $10.6 \%$ ) were more common among patients assigned to aspirin and ER-DP. The PRoFESS trial revealed that neither aspirin with ER-DP nor clopidogrel influence cognitive and functional outcome, despite indications from experiments in animals.

\section{ANTIPLATELETS AFTER BLEEDING}

According to the recommendations of the American college of cardiology foundation (ACCF), the American college of gastroenterology, and the American heart association (AHA), decision for discontinuation of ASA in the setting of acute ulcer bleeding after low-dose aspirin, must be made on an individual basis to discern potential thrombotic and hemorrhagic complications. Patients receiving low-dose ASA who develop upper GI bleeding are often advised to discontinue ASA until ulcers have healed (Bhatt et al., 2008). There is no evidence that non-ASA antiplatelet drugs such as clopidogrel will reduce this bleeding risk in the presence of active ulcers (Lanas et al., 2006).

\section{COMPARISONS}

The recommendations of AHA and European stroke organization (ESO) for prevention of Stroke and TIA have several differences concerning class and level of evidence of antiplatelet agent (Table 1).

For the patients undergoing carotid endarterectomy (CEA) Aspirin (81-325 mg daily) is recommended before CEA and may be continued indefinitely postoperatively (Class I, Level A). For the patients undergoing carotid artery stenting (CAS) is recommended to use before and for a minimum of 30 days after

Table 1 | Recommendations for antiplatelet therapy in secondary stroke prevention for non-cardioembolic ischemic stroke or TIA.

\begin{tabular}{|c|c|c|}
\hline Recommendations & ESO & AHA \\
\hline It is recommended that patients receive antithrombotic therapy & Class I, Level A & Class I, Level A \\
\hline \multicolumn{3}{|l|}{ Initial therapy } \\
\hline Combination aspirin $25 \mathrm{mg}+$ ER-DP & Class I, Level A & Class I, Level B \\
\hline \multicolumn{3}{|l|}{$200 \mathrm{mg}$ twice a day } \\
\hline For patients allergic to aspirin, clopidogrel is reasonable & - & Class IIA, Level B \\
\hline $\begin{array}{l}\text { The combination of aspirin and clopidogrel is not recommended in patients } \\
\text { with recent ischemic stroke, except in patients with specific indications } \\
\text { (e.g., unstable angina or non-Q-wave Ml, or recent stenting) }\end{array}$ & Class I, Level A & Class I, Level A \\
\hline $\begin{array}{l}\text { For patients who have an ischemic stroke while taking aspirin, there is no } \\
\text { evidence that increasing dose of aspirin provides additional benefit }\end{array}$ & - & Class IIB, Level C \\
\hline
\end{tabular}




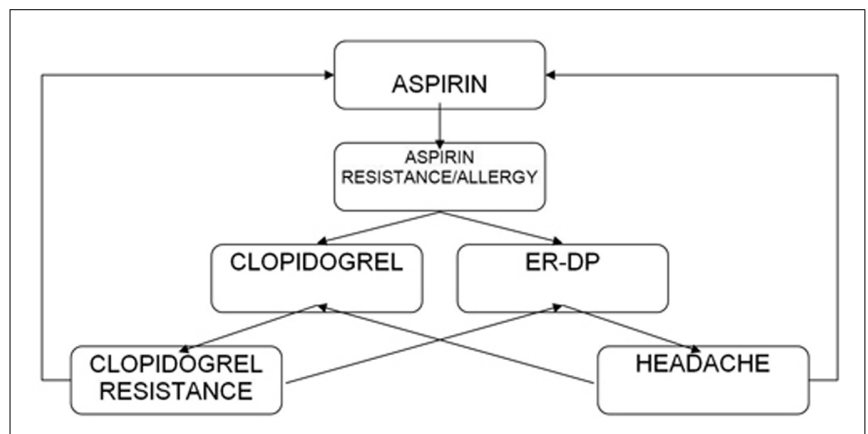

FIGURE 1 | Selection of individual antiplatelet agents.

CAS, dual-antiplatelet therapy with aspirin (81-325 mg daily) plus clopidogrel (75 mg daily). For patients intolerant of clopidogrel, ticlopidine (250 mg twice daily) may be substituted. (Class I, Level C; Brott et al., 2011).

For patients who have an ischemic stroke while taking aspirin, there is no evidence that increasing the dose of aspirin provides additional benefit. Unfortunately, there have been any trial to indicate that switching antiplatelet agents reduces the risk for subsequent events. Although alternative antiplatelet agents are often considered for non-cardioembolic patients, no single agent or combination has been studied in patients who have had an event while receiving aspirin (Ringleb et al., 2008; Furie et al., 2011). The selection of an antiplatelet agent should be individualized on the basis of patient risk factor profiles (Figure 1).

\section{CONCLUSION}

According to the results of the accomplished studies it is difficult to broadly recommend one antithrombotic agent in favor of the other. Instead, a review of the currently published data suggests the importance of focusing on the individualizing approach in antiplatelet therapy.

Aspirin plus ER-DP or clopidogrel alone may be of more benefit in recurrent stroke prevention than aspirin alone. Clopidogrel is an alternative for those with allergy to aspirin or gastrointestinal side effects. For patients who do not tolerate dipyridamole because of headache, either aspirin or clopidogrel is appropriate.

There are few ongoing trials on new antithrombotic drugs.

\section{REFERENCES}

Algra, A., and van Gijn, J. (1999). Cumulative meta-analysis of aspirin efficacy after cerebral ischaemia of arterial origin. J. Neurol. Neurosurg. Psychiatr. 66, 255

Antithrombotic Trialists' Collaboration. (2002). Collaborative meta-analysis of randomised trials of antiplatelet therapy for prevention of death, myocardial infarction, and stroke in high risk patients. BMJ 324, 71-86. doi: 10.1136/bmj.324.7329.71

Bhatt, D., Fox, K., Hacke, W., Berger, P., Black, H., Boden, W., Cohen, E., Creager, M., Easton, D., Flather, M., Haffner, S., Hamm, C., Hankey, G., Johnston, C., Mak, K., Mas, J., Montalescot, G., Pearson, T., Steg, G., Steinhubl, S., Weber, M., Brennan, D., Fabry-Ribaudo, L., Booth, J., Topol, E., and CHARISMA Investigators. (2006). Clopidogrel and aspirin versus aspirin alone for the prevention of atherothrombotic events. N. Engl. J. Med. 354, 1706-1717.

Bhatt, D., Flather, M., Hacke, W., Berger, P., Black, H., Boden, W., Cacoub, P., Cohen, E., Creager, M., Easton, D., Hamm, C., Hankey, G., Johnston, C., Mak, K., Mas, J., Montalescot, G., Pearson, T. P., Steg, P., Steinhubl, S., Weber, M., Fabry-Ribaudo, L., Hu, T., Topol, E., Fox, K., and CHARISMA Investigators. (2007). Patients with prior myocardial infarction, stroke, or symptomatic peripheral arterial disease in the CHARISMA trial. J. Am. Coll. Cardiol. 49, 1982-1988.

Bhatt, D., Scheiman, J., Abraham, N. S., Antman, E. M., Chan, F., Furberg, C., Johnson, D., Mahaffey, K., Quigley, E., Harrington, R., Bates, E., Bridges, C., Eisenberg, M., Ferrari, V., Hlatky, M., Kaul, S., Lindner, J., Moliterno, D., Mukherjee, D., Schofield, R., Rosenson, R., Stein, J., Weitz, H., and Wesley, D. J. (2008). ACCF/ACG/AHA 2008 expert consensus document on reducing the gastrointestinal risks of antiplatelet therapy and NSAID use: a report of the American college of cardiology foundation task force on clinical expert. J. Am. Coll. Cardiol. 52, 1502-1517.

Brott, T. G., Halperin, J. L., Abbara, S., Bacharach, J., Barr, J. D., Bush, R., Cates, C., Creager, M., Fowler, S., Friday, G., Hertzberg, V., McIff, B., Moore, W., Panagos, P., Riles, T., Rosenwasser, R., and Taylor, A. (2011). ASA/ACCF/AHA/AANN/AANS/AC R/ASNR/CNS/SAIP/SCAI/SIR/SNI S/SVM/SVS guideline on the management of patients with extracranial carotid and vertebral artery disease. J. Am. Coll. Cardiol. 57, e16-e94. [originally published online Jan 31, 2011; doi:10.1016/j.jacc.2010.11.006].

Brunton, L., Lazo, J., and Parker, K. (2005). Goodman and Gilman's The Pharmacological Basis of Therapeutics, New York, NY: McGraw-Hill Professional.
Campbell, C. L., Smyth, S., Montalescot, G., and Steinhubl, S. R. (2007). Aspirin dose for the prevention of cardiovascular disease. A systematic review. JAMA 297, 2018-2024.

CAPRIE Steering Committee. (1996). A randomised, blinded, trial of clopidogrel versus aspirin in patients at risk of ischaemic events (CAPRIE). Lancet 348, 1329-1339.

Connolly, S., Pogue, J., Hart, R., Hohnloser, S., Pfeffer, M., Chrolavicius, S., and Yusuf, S. (2009). Effect of clopidogrel added to aspirin in patients with atrial fibrillation. N. Engl. J. Med. 360, 2066-2078.

Costa, J., Ferro, J., Matias-Guiu, J., Alvarez-Sabin, J., and Torres, F. (2005). Triflusal for preventing serious vascular events in people at high risk. Cochrane Database Syst. Rev. CD004296.

Diener, H., Bogousslavsky, J., Brass, L., Cimminiello, C., Csiba, L., Kaste, M., Leys, D., Matias-Guiu, J., Rupprecht, H., and MATCH investigators. (2004). Aspirin and clopidogrel compared with clopidogrel alone after recent ischemic stroke or transient ischemic attack in high-risk patients (MATCH): randomized, double-blind, placebocontrolled trial. Lancet 364, 331-337.

Diener, H., Cunha, L., Forbes, C., Sivenius, J., Smets, P., and Lowenthal, A. (1996). European stroke prevention study 2. Dipyridamole and acetyl- salicylic acid in the secondary prevention of stroke. J. Neurol. Sci. 143, $1-13$.

Eikelboom, J., Emery, J., and Hankey, D. (2010). The use of platelet function assays may help to determine appropriate antiplatelet treatment options in a patient with recurrent stroke on baby aspirin: against. Stroke 41, 2398-2399.

Furie, K., Kasner, S., Adams, R., Albers, G., Bush, R., Fagan, S., Halperin, J., Johnston, S., Katzan, I., Kernan, W., Mitchell, P., Ovbiagele, B., Palesch, Y., Sacco, R., Schwamm, L., Wassertheil-Smoller, S., Turan, T., and Wentworth, D. (2011). Guidelines for the prevention of stroke in patients with stroke or transient ischemic attack: a guideline for healthcare professionals from the American Heart Association/American Stroke Association. Stroke 42, 227-276.

Gorelick, P., Born, G., D’Agostino, R., Hanley, D., Moye, L., and Pepine, C. J. (1999). Therapeutic benefit. Aspirin revisited in light of the introduction of clopidogrel. Stroke 30, 1716-1721.

Gorelick, P., Richardson, D., Kelly, M., Ruland, S., Hung, E., Harris, Y., Kittner, S., Leurgans, S., and African American Antiplatelet Stroke Prevention Study Investigators. (2003). Aspirin and ticlopidine for prevention of recurrent stroke in black patients: a randomized trial. JAMA 289, 2947-2957. 
Gurbel, P., Cummings, C., Bell, C., Alford, A., Meister, A., Serebruany, V., and Plavix Reduction Of New Thrombus Occurrence (PRONTO) trial. (2003). Onset and extent of platelet inhibition by clopidogrel loading in patients undergoing elective coronary stenting: the plavix reduction of new thrombus occurrence (PRONTO) trial. Am. Heart J. 145, 239-247.

Halkes, P. H., van Gijn, J., Kappelle, L. J., Koudstaal, P. J., Algra A., and ESPRIT Study Group. (2006). Aspirin plus dipyridamole versus aspirin alone after cerebral ischemia of arterial origin (ESPRIT): randomized controlled trial. Lancet 367, 1665-1673.

Halkes, P. H. A., van Gijn, J., Kappelle, L. J., Koudstaal, P. J., Algra, A., and ESPRIT study group. (2009). Risk indicators for development of headache during dipyridamole treatment after cerebral ischaemia of arterial origin. J. Neurol. Neurosurg. Psychiatry 80, 437-439.

Hankey, G. J., Spiesser, J., Hakimi, Z., Bego, G., Carita, P., and Gabriel, S. (2007). Rate, degree, and predictors of recovery from disability following ischemic stroke. Neurology 68, 1583-1587.

Hankey, J., Hacke, W., Easton, D., Johnston, C., Mas. L., Brennan, D., Bhatt, D., Fox, K., and Topol, E. (2010). Effect of clopidogrel on the rate and functional severity of stroke among high vascular risk patients: a prespecified substudy of the clopidogrel for high atherothrombotic risk and ischemic stabilization, management and avoidance (CHARISMA) trial. Stroke 41, 1679-1683.

Holmes, D., Dehmer, G., Kaul, S., Leifer, D., O'Gara, P., and Stein, M. (2010). ACFF/AHA clopidogrel clinical alert: approach to the FDA "boxed warning." Circulation 122, 537-557.

Kennedy, J., Hill, M. D., Ryckborst, K. J., Eliasziw, M., Demchuk, A. M., and Buchan, A. M. (2007). Fast assessment of stroke and transient ischaemic attack to prevent early recurrence (FASTER): a randomised controlled pilot trial. Lancet Neurol. 6, 961-969.

Lanas, A., Garcia-Rodriguez, L., Arroyo, M., Gomollón, F., Feu, F., GonzálezPérez, A., Zapata, E., Bástida, G., Rodrigo, L., Santolaria, S., Güell, M., de Argila, C., Quintero, E., Borda, F., and Piqué, J. (2006). Risk of upper gastrointestinal ulcer bleeding associated with selective cyclooxygenase-2 inhibitors, traditional non-aspirin non-steroidal antiinflammatory drugs, aspirin and combinations. Gut 55, 1731-1738.

McQuaid, K. R., and Laine, L. (2006). Systematic review and meta-analysis of adverse events of low-dose aspirin and clopidogrel in randomized controlled trials. Am. J. Med. 119, 624-638.

Mega, J., Close, S., Wiviott, S., Shen, L., Hockett, R., Brandt, J., Walker, J., Antman, E., Macias, W., Braunwald, E., and Sabatine, M. (2009). Cytochrome P-450 polymorphisms and response to clopidogrel. N. Engl. J. Med. 360, 354-362.

Ohira, T., Shahar, E., Chambless, L., Rosamond, W., Mosley, J., and Folsom, A. (2006). Risk factors for ischemic stroke subtypes: the atherosclerosis risk in communities study. Stroke 37, 2493-2498.

Qureshi, A., Luft, A., Sharma, M., Guterman, L., and Hopkins, L. (2000). Prevention and treatment of thromboembolic and ischemic complications associated with endovascular procedures, part I: pathophysiological and pharmacological features. Neurosurgery 46, 1344-1359.

Ringleb, P., Bousser, M., Ford, G., Bath, P., Brainin, M., Caso, V., Cervera, A., Chamorro, A., Cordonnier, C., Csiba, L., Davalos, A., Diener, H., Ferro, J., Hacke, W., Hennerici, M., Kaste, M., Langhorne, P., Lees, K., Leys, D., Lodder, J., Hugh, S., Markus, H., Mas, J., Mattle, H., Muir, K., Norrving, B., Obach, V., Paolucci, S., Ringelstein, E., Schellinger, P.,
Sivenius, J., Skvortsova, V., Sunnerhagen, K., Thomassen, L., Toni, D., von Kummer, R., Wahlgren, N., Walker, M., and Wardlaw, J. (2008) ESO - Guidelines for management of ischaemic stroke. Cerebrovasc. Dis. 25, 457-507.

Roth, G. J., and Calverley, D. C. (1994). Aspirin, platelets, and thrombosis: theory and practice. Blood 83 885-898.

Sacco, R., Diener, H., Yusuf, S., Cotton, D., Ounpuu, S., Lawton, W., Palesch, Y., Martin, R., Albers, G., Bath, P., Bornstein, N., Chan, B., Chen, S., Cunha, L., Dahlöf, B., De Keyser, J., Donnan, G., Estol, C., Gorelick, P., Gu, V., Hermansson, K., Hilbrich, L., Kaste, M., Lu, C., Machnig, T., Pais, P., Roberts, R., Skvortsova, V., Teal, P., Toni, D., VanderMaelen, C., Voigt, T., Weber, M., Yoon, B., and PRoFESS Study Group. (2008). Aspirin and extended-release dipyridamole versus clopidogrel for recurrent stroke. N. Engl. J. Med. 359, 1238-1251.

Schuldiner, A. R., O'Connell, J. R., Bliden, K. P., Gandhi, A., Ryan, K., Horenstein, R., Damcott, C. Pakyz, R., Tantry, U., Gibson, Q., Pollin, T., Post, W., Parsa, A., Mitchell, B., Faraday, N., Herzog, W., and Gurbel, P. (2009). Association of cytochrome P450 2C19 genotype with the antiplatelet effect and clinical efficacy of clopidogrel therapy. JAMA 302, 849-858.

Selim, M., and Molina, C. (2010). Platelet function assays in stroke management: more study is needed. Stroke. 41, 2396-2397.

Shin, D., Lee, P., and Bang, O. (2005). Mechanisms of recurrence in subtypes of ischemic stroke: a hospitalbased follow-up study. Arch. Neurol. 62, 1232-1237.

Siller-Matula, J., Spiel, A., Lang, I., Kreiner, G., Christ, G., and Jilma, B. (2009). Effects of pantoprazole and esomeprazole on platelet inhibition by clopidogrel. Am. Heart J. 157, 148.e1-148.e5.
Steg, P. G., Bhatt, D. L., Wilson, P. W., D’Agostino, Sr. R., Ohman, E. M., Rother, J., Liau, C., Hirsch, A., Mas, J., Ikeda, Y., Pencina, M., Goto, S., and REACH Registry Investigators. (2007). One-year cardiovascular event rates in outpatients with atherothrombosis. JAMA 297 1197-1206.

The Clopidogrel in Unstable Angina to Prevent Recurrent Events Trial Investigators. (2001). Effects of clopidogrel in addition aspirin in patients with acute coronary syndromes without ST-segment elevation. N. Engl. J. Med. 345, 494-502.

The Dutch TIA Trial Study Group. (1991). A comparison of two doses of aspirin ( $30 \mathrm{mg}$ vs. $283 \mathrm{mg}$ a day) in patients after a transient ischemic attack or minor ischemic stroke. $N$. Engl. J. Med. 325, 1261-1266.

The ESPS-2 Group. (1997). European Stroke Prevention Study: 2. Efficacy and safety data. Secondary endpoints. J. Neurol. Sci. 151(Suppl.), S27-S37.

Conflict of Interest Statement: The authors declare that the research was conducted in the absence of any commercial or financial relationships that could be construed as a potential conflict of interest.

Received:09 January 2011; paper pending published: 28 February 2011; accepted: 17 May 2011; published online: 04 July 2011. Citation: Shulga $O$ and Bornstein $N$ (2011) Antiplatelets in secondary stroke prevention. Front. Neur. 2:36. doi: 10.3389/fneur.2011.00036

This article was submitted to Frontiers in Stroke, a specialty of Frontiers in Neurology.

Copyright (c) 2011 Shulga and Bornstein. This is an open-access article subject to a non-exclusive license between the authors and Frontiers Media SA, which permits use, distribution and reproduction in other forums, provided the original authors and source are credited and other Frontiers conditions are complied with. 